Revista de la red interuniversitaria de estudios sobre las literaturas rioplatenses contemporáneas en Francia

$18 \mid 2018$

El río y la ciudad

\title{
Presentación
}

\section{Laura Gentilezza}

URL: http://journals.openedition.org/lirico/5899

DOI: 10.4000/lirico.5899

ISSN: 2262-8339

Editor

Réseau interuniversitaire d'étude des littératures contemporaines du Río de la Plata

\section{Referencia electrónica}

Laura Gentilezza, «Presentación », Cuadernos LIRICO [En línea], 18 | 2018, Puesto en línea el 13

noviembre 2018, consultado el 02 mayo 2019. URL : http://journals.openedition.org/lirico/5899 ; DOI : 10.4000/lirico.5899

Este documento fue generado automáticamente el 2 mayo 2019.

\section{(c) (1) $\Theta \Theta$}

Cuadernos LIRICO está distribuido bajo una Licencia Creative Commons Atribución-NoComercialSinDerivar 4.0 Internacional. 


\title{
Presentación
}

\author{
Laura Gentilezza
}

1 En el marco del coloquio Le fleuve et la ville. Possibilités descriptives d'une transformation permanente y del número 18 de Cuadernos LIRICO, críticos, investigadores, artistas y escritores fueron convocados para poner de manifiesto la experiencia del vínculo entre el río y la ciudad. La propuesta se alejaba del marco académico en el que se inscribieron las ponencias del coloquio y los artículos de la revista y daba lugar a manifestaciones escritas y audiovisuales en donde cada creador encontrara su forma más adecuada. Como resultado recibimos más de cincuenta trabajos creativos de diferente índole de los que ofrecemos aquí una selección. El dossier completo, que formará parte del volumen El río y la ciudad, será publicado próximamente por la editorial de la Universidad Nacional de Entre Ríos (EDUNER) en su colección "El país del sauce".

2 La invitación que realizamos ${ }^{1}$ buscaba exponer las modulaciones de un par en torno al que gravitan muchas de las poéticas, de las estéticas y del pensamiento tanto en el ámbito americano como europeo. Entre ambos, el río fue la imagen más pregnante, la ciudad lo acompaña. Y esa compañía va declinándose a través de distintas figuras en todo el corpus reunido: la ilustración, la variación, la observación y el ejercicio son algunas de las articulaciones que fueron produciendo los participantes.

3 El material que aquí reunimos representa las distintas aproximaciones a esta cuestión. Tanto el teatro de recortes "Cuadernos del Tigre" de Eduardo Stupía y Daniel Samoilovich como "Ustia" de Rodrigo Moreno trabajan la ilustración y el relato a través de la experiencia audiovisual. La variación de fotografías de Graciela Villanueva establece un vínculo entre imagen y palabra que cuestiona la noción de ilustración y renueva ese binomio también trabajado por Raúl Antelo, Guillaume Contré, Hernán Hevia, Cristina Iglesia, Claudia Torre y Marta Waldegaray.

4 La lectura como praxis y el vínculo vital con el río como paisaje cotidiano se vislumbran en los trabajos de Sergio Chejfec, Loreley El Jaber, Sergio Delgado, Sonia Scarabelli, Miguel Ángel Petrecca, Martín Kohan y Enrique Fernández. Tanto en ellos como en el relato de Alejandra Costamagna el espacio literario abierto en el lector por otros textos modifica su relación con la experiencia del río y crea, como lo hace el cine en el texto de David Oubiña, un nuevo modo de percepción en el espectador-lector. Si el vínculo entre palabra 
e imagen es cuestionado en este corpus, la imagen poética puede entonces agregar a esta discusión algún elemento como ocurre en el trabajo tipográfico de Daniel Link y en el ejercicio de escritura, una forma ya clásica en el proyecto de Alejandro Zambra.

5 En esta selección se retoman, bajo otra forma y con nuevas perspectivas, las ideas y discusiones que tuvieron lugar durante el coloquio, pero también nuevas ideas, discusiones y perspectivas inesperadas que continuarán en el libro. Les deseamos buena lectura.

NOTAS

1. Para mayores referencias, ver en la Introducción a este número: Sergio Delgado y Enrique Fernández Domingo, "Posibilidades descriptivas de una transformación permanente", § 5 (N. de los E.). 